\title{
Propylene Glycol Improves Stability of the Anti-Inflammatory Compounds in Scutellaria baicalensis Extract
}

\author{
Tseng-Ting Kao ${ }^{1}$, Ming-Chao Wang ${ }^{1}$, Yi-Hsuan Chen ${ }^{2}$, Yu-Tung Chung ${ }^{1}$ and Pai-An Hwang ${ }^{2,3, *}$ \\ 1 Animal Technology Research Center, Agricultural Technology Research Institute, No.1, Ln. 51, Dahu Rd., \\ Xiangshan District, Hsinchu City 300, Taiwan; kaott@mail.atri.org.tw (T.-T.K.); \\ 1072039@mail.atri.org.tw (M.-C.W.); ydc@mail.atri.org.tw (Y.-T.C.) \\ 2 Department of Bioscience and Biotechnology, National Taiwan Ocean University, No.2, Beining Rd., \\ Jhongiheng District, Keelung City 202, Taiwan; 1093B014@email.ntou.edu.tw \\ 3 Center of Excellence for the Oceans, National Taiwan Ocean University, No.2, Beining Rd., \\ Jhongjheng District, Keelung City 202, Taiwan \\ * Correspondence: amperehwang@ntou.edu.tw; Tel.: +886-2-2462-2192; Fax: +886-2-2463-4732
}

Citation: Kao, T.-T.; Wang, M.-C.; Chen, Y.-H.; Chung, Y.-T.; Hwang, P.-A. Propylene Glycol Improves Stability of the Anti-Inflammatory Compounds in Scutellaria baicalensis Extract. Processes 2021, 9, 894. https://doi.org/10.3390/pr9050894

Academic Editor: Shao-Wen Hung

Received: 26 April 2021

Accepted: 16 May 2021

Published: 19 May 2021

Publisher's Note: MDPI stays neutral with regard to jurisdictional claims in published maps and institutional affiliations.

Copyright: (c) 2021 by the authors. Licensee MDPI, Basel, Switzerland. This article is an open access article distributed under the terms and conditions of the Creative Commons Attribution (CC BY) license (https:// creativecommons.org/licenses/by/ $4.0 /)$.

\begin{abstract}
Scutellaria baicalensis root extracts have been useful for external skin care and have been commercialized for years. Here, a comprehensive study was conducted to investigate the difference between $20 \%$ propylene glycol (PG) and water used as the storage solvent for a time course analysis of their remaining biological activities and ingredient compositions versus their freshly prepared conditions. Of the four major components in the $20 \%$ PG solvent, more than $80 \%$ of the components were retained after storage for two months, but in water only baicalin and wogonin were retained. The relative antibacterial activities, antioxidant properties and anti-inflammatory activities of the $20 \%$ PG solvent group were better than those of the water solvent group. Taken together, we demonstrated that these activities improved when PG, a common solvent used in many product formulas, was used as the storage solvent for the S. baicalensis extract.
\end{abstract}

Keywords: Scutellaria baicalensis; storage solvent; propylene glycol; anti-inflammation

\section{Introduction}

Scutellaria baicalensis Georgi (Huang-qin in Chinese) is one of the most widely used traditional Chinese medicines and is officially listed in the Chinese Pharmacopoeia. This plant is widely distributed, especially in China, Korea, Japan, Taiwan and India, and it is also found in Far East Russia, Siberia and Mongolia. In Taiwan, S. baicalensis has been introduced as a medicinal plant [1] and is now planted under the Taiwan Good Agriculture Practice (TGAP). S. baicalensis contains various bioactive flavonoid components, and the four major bioactive components are baicalin, its aglycone baicalein, wogonoside and its aglycone wogonin [2]. These flavonoids have a wide variety of physiological activities, whether they are taken internally or externally. Recently, S. baicalensis extracts have attracted interest worldwide for their external skin care and cosmeceutical benefits.

In a skin care application study, it was found that the S. baicalensis extract offered protection against ultraviolet A (UVA)-induced aging responses from skin fibroblasts, such as a reduction in telomere length, increased malonyldialdehyde (MDA) formation and expression of the enzyme matrix metalloproteinase-1 (MMP-1) [3]. It has also been observed that the $S$. baicalensis extract promotes keratinocyte differentiation and helps restore skin barrier function via activation of peroxisome proliferator-activated receptor (PPAR)- $\alpha$ [4]. Furthermore, S. baicalensis presents antioxidant activity [5], anti-inflammatory activity [6] and antibacterial activity [7], thus showing the potential use of the S. baicalensis extract as an antiallergic and anti-inflammatory agent for skin care. In the cosmeceutical industry, functional extracts are usually sold in a liquid form in order to facilitate distribution throughout the product. The chemical structures of the main bioactive components of 
S. baicalensis include baicalin, baicalein, wogonoside and wogonin (Figure 1), which are lipid-soluble substances. Thus, ethanol and other organic solvents must be used for extraction, but organic solvents are not desirable for skin care development [8]. Therefore, $\mathrm{Ni}$ et al. [8] and Choi et al. [9] used water as the extraction solvent to optimize the water extraction process of $S$. baicalensis.<smiles>O=C(O)[C@H]1O[C@@H](Oc2cc3oc(-c4ccccc4)cc(=O)c3c(O)c2O)[C@H](O)[C@@H](O)[C@@H]1O</smiles>

Baicalin<smiles>O=c1cc(-c2ccccc2)oc2cc(O)c(O)c(O)c12</smiles>

Baicalein<smiles>COc1c(O[C@@H]2OC(C(=O)O)[C@H](O)[C@H](O)[C@H]2O)cc(O)c2c(=O)cc(-c3ccccc3)oc12</smiles>

Wogonoside<smiles>COc1c(O)cc(O)c2c(=O)cc(-c3ccccc3)oc12</smiles>

Wogonin

Figure 1. Chemical structures of baicalin, wogonoside, baicalein and wogonin.

Stability investigations are often sought by manufacturers to study degradation, which is usually caused by time, temperature, $\mathrm{pH}$, moisture, light, storage solvent, etc., and their relative impacts on the quality of functional extracts [10]. Xing et al. [11] found that baicalin is stable in acidic and organic solutions but unstable in basic solutions and that adding vitamin $\mathrm{C}$ and $\mathrm{HCl}$ to baicalein samples can improve their stability in biological fluids. Qiu et al. [12] reported that a relatively lower temperature is conducive to baicalein stability. Feng et al. [13] published a detailed report on the stability of baicalin and baicalein in phosphate buffer and biological fluids in vitro and showed that acidic environments $(\mathrm{pH} 2-4.5)$, lower temperatures $\left(<4{ }^{\circ} \mathrm{C}\right)$ and acidic antioxidants (e.g., vitamin $\mathrm{C}$ ) were conducive to stabilizing them. Based on the above literature, we know that current research on stability is focused on the degradation or biotransformation in biological fluids, as well as $\mathrm{pH}$ and temperature changes. Moldovan et al. [14] demonstrated that storage solvent is one of the important factors affecting degradation because phenolic compound storage in water or ethanol can result in different degradation processes. However, to date, information is not available in the literature regarding the degradation of the bioactive components of $S$. baicalensis, including baicalin, baicalein, wogonoside and wogonin, in different storage solvents. Although some solutions have overcome the degradation problems of individual components of the $S$. baicalensis extract, workable storage options remain an unmet need for industrial use, not only concerning component stability but also to maintain the extract functions.

Propylene glycol (PG) is a synthetic liquid substance that absorbs water and is used by the chemical, food, and pharmaceutical industries. The Food and Drug Administration (FDA) has classified PG as an additive that is "generally recognized as safe" for use in food. It is used to absorb extra water and maintain moisture in certain medicines, cosmetics, and food products (https:/ / www.accessdata.fda.gov/scripts/cdrh/cfdocs/cfcfr/ CFRSearch.cfm?fr=184.1666\&SearchTerm=propylene\%20glycol (accessed on 1 April 2020)). 
The European Medicines Agency EMA/CHMP/704195/2013 (published 09/10/2017) [15] reported that PG is used as a humectant in topicals $(15 \%)$, as a preservative in solutions $(15-30 \%)$ or as a co-solvent in aerosols (10-25\%). The usual concentration of PG in external products is between 10 and $30 \%$, so we choose the median value of $20 \%$ PG as the storage solvent in the present study. To predict the quality changes of the bioactive components of S. baicalensis during storage, our study used $20 \%$ PG and water as the storage solvents to determine the changes in antibacterial activity, antioxidant activity, anti-inflammatory activity, phototoxicity potential and comparison of baicalin, baicalein, wogonoside and wogonin contents. The conditions investigated here ensure high compatibility with storage and processing techniques generally applied in the skin care and pharmaceutical industries.

\section{Materials and Methods}

\subsection{Plant Material, Reagents and Media}

The plant material S. baicalensis used in this study was cultivated and produced by following Taiwan Good Agricultural Practice (TGAP) guidance. The dry roots of S. baicalensis were kindly provided by Dr. Tung-Wu Chang (Hualien District Agricultural Research and Extension Station Council of Agriculture, Executive Yuan, R.O.C.). Dulbecco's phosphate-buffered saline (DPBS) and Hank's balanced salt solution (HBSS, 21-023-CRV) were purchased from Corning (Manassas, VA, USA). PG was purchased from 63 PURE CHEMICALS (Taipei, Taiwan) with a purity $>=98 \%$. Baicalin (cat. no CFN99111), wogonoside (cat. no CFN99710), baicalein (cat. no CFN98783) and wogonin (cat. no CFN97089) were purchased from ChemFaces (Wuhan, China) with purities $>=98 \%$. All other chemicals were purchased from Sigma-Aldrich (St. Louis, MO, USA).

\subsection{Preparation of the S. baicalensis Extract (SBE) and Storage Conditions}

Five hundred grams of the dry roots of $S$. baicalensis were ground to a powder with particle sizes of less than $2 \mathrm{~mm}$. The dry root powder was extracted with 60 liters of $\mathrm{RO}$ water at $80^{\circ} \mathrm{C}$ for $2 \mathrm{~h}$. The extract was freeze-dried until the water content was less than $1 \%$ in the final S. baicalensis extract (SBE) powders. The yield was $36.33 \%$ based on the dry weight of the S. baicalensis roots. For the storage test, a stock solution of the abovementioned SBE was prepared at a concentration of $10 \mathrm{mg} / \mathrm{mL}$ in distilled water or $20 \%$ PG. Both stock solutions were sterilized by passage through a $0.22 \mu \mathrm{m}$ polyethersulfone (PES) filter, aliquoted into six $1 \mathrm{~mL}$ Eppendorf tubes and then stored in the dark at room temperature until the day for assays. In this study, we prepared three independent samples of each condition and storage time in order to reduce the impact of changes from external environmental factors and pollution during sample unpacking.

\subsection{Characterization of the Bioactive Compounds from S. baicalensis by High Performance Liquid Chromatography (HPLC)}

Ten micrograms of each SBE stock solution were prepared for analysis by a Waters HPLC system, which consisted of a pump controller (Waters 600), an autosampler (Waters 717 plus) with cooler, a photodiode array detector (Waters 996) and a Prodigy ODS (2) column $(5 \mu \mathrm{m}, 150 \times 3.2 \mathrm{~mm}, 150 \AA$, Phenomenex $)$ with a guard column $(5 \mu \mathrm{m}$, $20 \times 4 \mathrm{~mm}$, YMC-Pack Pro C18). The mobile phase was composed of buffer A (acetonitrile with $0.1 \%$ trifluoroacetic acid (TFA) (v/v)) and buffer B (distilled water with $0.1 \%$ TFA $(\mathrm{v} / \mathrm{v}))$ with a gradient elution program of $10 \sim 57 \%$ buffer A (0-25 min), 57 57\% buffer A (25-30 $\mathrm{min}$ ), 57 90\% buffer A (30-37 $\mathrm{min}$ ) and 90 10\% buffer A (37-38 $\mathrm{min}$ ). The flow rate was $1.0 \mathrm{~mL} / \mathrm{min}$, and the detection wavelength was $280 \mathrm{~nm}$. For quantitative determinations, the standard curves of baicalin, wogonoside, baicalein and wogonin were established in the range of 0.5 to $25 \mu \mathrm{g}$ against the relative peak areas, with linear regression coefficients of $>0.997$. The standard solution was prepared in dimethyl sulfoxide at a concentration of $5 \mathrm{mg} / \mathrm{mL}$ for each compound. 


\subsection{Antibacterial Activity}

Propionibacterium acnes (BCRC 10723) and Staphylococcus aureus (BCRC 14980) (Bioresource Collection and Research Center, Taiwan) were cultured in Reinforced Clostridial Medium under anaerobic conditions in a Gas-pak at $37^{\circ} \mathrm{C}$ or in Tryptic soy broth under aerobic conditions at $37^{\circ} \mathrm{C}$, respectively. A total of $100 \mu \mathrm{L}$ of SBE stock solution $(10 \mathrm{mg} / \mathrm{mL})$ was added to an inoculum containing $100 \mu \mathrm{L}$ of bacteria in a 96-well plate. After $24 \mathrm{~h}$ of incubation, the optical density (OD) of the culture medium was measured using a spectrophotometer at a wavelength of $600 \mathrm{~nm}$. The relative antibacterial activity (R\%) was calculated as follows: $\mathrm{R} \%=(\mathrm{OD}$ growth medium-OD sample $) / \mathrm{OD}$ growth medium $\times 100 \%$.

\subsection{Antioxidant Activity by the 1, 1-Diphenyl-2-picrylhydrazyl (DPPH) Radical Scavenging Method}

The DPPH radical scavenging determination was performed according to the method described by Okawa et al. [16]. Equal volumes of the test sample and DPPH working reagent were added to a 96-well plate, gently mixed by pipetting and then left to stand for $30 \mathrm{~min}$ in the dark at room temperature. After incubation, the absorbance of the plate was measured at $517 \mathrm{~nm}$ with a plate reader (Sunrise, TECAN, Switzerland). A mixture of the tested sample and pure methanol and a mixture of DPPH working reagent and sample diluted solvent served as the blank and blind controls, respectively. The OD of the assay was measured using a spectrophotometer at a wavelength of $517 \mathrm{~nm}$. The equation used to calculate DPPH scavenging was as follows: DPPH scavenging $\%=[1-(\mathrm{OD}$ SBE stock - OD blank)/(OD blind)] × 100\%. The EC50 value was determined by using GraphPad Prism version 5 software and analyzed by nonlinear regression (curve fit).

\subsection{Cell Culture}

Human keratinocytes (ATCC CRL-2309) were grown and maintained in Defined Keratinocyte-serum-free medium (SFM) (Gibco 10744-019) with Defined KeratinocyteSFM Growth Supplement, and the concentrations added followed the manufacturer's instructions. The plates were incubated at $37{ }^{\circ} \mathrm{C}$ in a humidified atmosphere with $5 \% \mathrm{CO}_{2}$.

\subsection{Intracellular Reactive Oxygen Species (ROS) Assay}

Assessment of the intracellular oxidative stress was conducted by using the cellpermeable fluorescent probe $2^{\prime}, 7^{\prime}$-Dichlorodihydrofluorescein diacetate (DCFH-DA), as described by Sittisart et al. [17], with certain modifications. Cells were seeded at $1.2 \times 10^{4}$ per well in a 96-well plate and incubated for $24 \mathrm{~h}$ with SBE stock solution (final concentration $50 \mu \mathrm{g} / \mathrm{mL}$ ). Then, $20 \mu \mathrm{M}$ DCFH-DA prepared in HBSS was added, and the cells were incubated in the dark for an additional $30 \mathrm{~min}$. DCFH-DA was removed by washing the cells with HBSS twice. Then, $250 \mu \mathrm{M} \mathrm{tBuOOH}$ was added, and the intensity of the fluorescence signal was immediately detected by a FLUOstar Omega microplate reader (BMG Labtech, Germany) with an excitation wavelength of $485 \mathrm{~nm}$ and an emission wavelength of $520 \mathrm{~nm}$. A time-dependent mode was used to record alterations in the fluorescent intensity over $60 \mathrm{~min}$ at $37^{\circ} \mathrm{C}$. The cells without stimulation by $\mathrm{tBuOOH}$ served as the control.

\subsection{IL-1 $\beta$ Secretion}

Cells were seeded at $1.2 \times 10^{4}$ per well in a 96-well plate and treated with $250 \mu \mathrm{M}$ $\mathrm{tBuOOH}$ with or without SBE stock solution (final concentration $50 \mu \mathrm{g} / \mathrm{mL}$ ) for $24 \mathrm{~h}$. Cells treated without $\mathrm{tBuOOH}$ and SBE stock were utilized as the control. The concentration of IL-1 $\beta$ was determined by using an enzyme-linked immunosorbent assay (ELISA) kit (R\&D Systems Inc., Minneapolis, MN) according to the manufacturer's instructions. 


\subsection{Phototoxicity Potential}

The phototoxic potential assay for keratinocytes was performed according to the method described by Amaral et al. [18] with certain modifications. Cells were seeded at $1.2 \times 10^{4}$ per well of a 96-well plate and treated with the photosensitive agent chlorpromazine (CPZ) (final concentration $9 \mu \mathrm{g} / \mathrm{mL}$ ) and SBE stock solution (final concentration $50 \mu \mathrm{g} / \mathrm{mL})$ for $1 \mathrm{~h}$. Then, one plate was exposed to UVA light $\left(1 \mathrm{~J} / \mathrm{cm}^{2}\right)$ by using VILBER LOURMAT, BIO-LINK ${ }^{\circledR}$ BLX-365 Crosslinker, and the other plate was kept in the dark as a nonirradiated control. Unwanted light exposure was minimized carefully during the whole procedure. The cell survival index was calculated for the cell proliferation of each treatment and normalized to the control, which was culture medium only. Cell proliferation was analyzed using the MTS/PMS assay (Promega G5421). Cells were reacted with MTS/PMS for $4 \mathrm{~h}$, and the absorbance was measured at $490 \mathrm{~nm}$ with a reference wavelength at $680 \mathrm{~nm}$ in a microplate reader (FLUOstar Omega, BMG Labtech, Germany).

\subsection{Statistical Analysis}

Statistical analysis of the data was performed using the one-way ANOVA and post hoc Tukey's multiple comparison tests with GraphPad Prism 5.0 (GraphPad Software, La Jolla, CA, USA).

\section{Results and Discussion}

3.1. Comparative Stabilities of Saicalin, Wogonoside, Baicalein and Wogonin after SBE Storage in $20 \%$ PG and Water

For the storage test, $\mathrm{SBE}$ was prepared as $10 \mathrm{mg} / \mathrm{mL}$ stock solutions in water and $20 \%$ PG and then stored in the dark at room temperature for two months. The phytochemical composition of SBE and four flavonoid standards (baicalin, wogonoside, baicalein and wogonin) at different storage times are shown in Figure 2. The representative constituents of the SBE were baicalin, wogonoside, baicalein and wogonin, and the two storage solvents did not affect the four flavonoids within $24 \mathrm{~h}$ (0 month) but showed some degradation after one month. The concentrations of these four flavonoids were calculated using their standard curves. The major constituent of the SBE was baicalin. In the SBE, the concentrations of baicalin, wogonoside, baicalein and wogonin were $270.05 \pm 2.71,57.50 \pm 4.32$, $19.24 \pm 1.01$ and $8.61 \pm 0.89 \mathrm{mg} / \mathrm{g}$, respectively.

The storage stabilities of baicalin, wogonoside, baicalein and wogonin from the SBE stored in 20\% PG and water are shown in Table 1. The profiles indicated no significant changes in baicalin content in the $20 \%$ PG solvent over two months. However, the baicalin content was significantly degraded in water after two months, and the retained \% was $92.41 \pm 0.84$. There was a difference in the degradation of wogonoside between the two different storage solutions. In $20 \%$ PG, wogonoside began to degrade significantly after two months of storage $(20 \%$ PG, two months, retained $\%: 80.85 \pm 3.11)$. However, after storage in water for one month, the degradation of wogonoside (water, one month, retained\%: $83.84 \pm 2.10$ ) was similar to that of $20 \%$ PG storage for two months. Baicalein showed strong degradation in water, with a retained $\%$ of less than $55 \%$ after one month, but it appeared to be more stable in $20 \%$ PG, with a retained \% of $84.28 \pm 1.80$ at month 2 . In both solvents, wogonin degraded as the storage time increased, and the solvents did not show significant differences after two months of storage. Our data show that the water solvent decreased the four major flavonoids in the order baicalein $>$ wogonoside $>$ wogonin $>$ baicalin, and the $20 \%$ PG solvent slightly decreased the four major flavonoids in the order of wogonoside $>$ baicalein, wogonin $>$ baicalin. Among these components, 20\% PG retained more than $80 \%$ of the contents after storage for two months. Therefore, $20 \%$ PG could maintain the stability of the four major flavonoids more effectively than water. It has been suggested that the solubility of flavonoids (such as hesperidin in lemon) is significantly higher in PG than in water [19]. With two hydroxyl groups, the results here show that PG is readily hydrated by surrounding water molecules through both hydrogen bond donation and acceptance [20]. Therefore, adding PG can lower the water activity to 
avoid chemical reactions and microorganism growth and enhance the apparent solubility of the active ingredients [21].
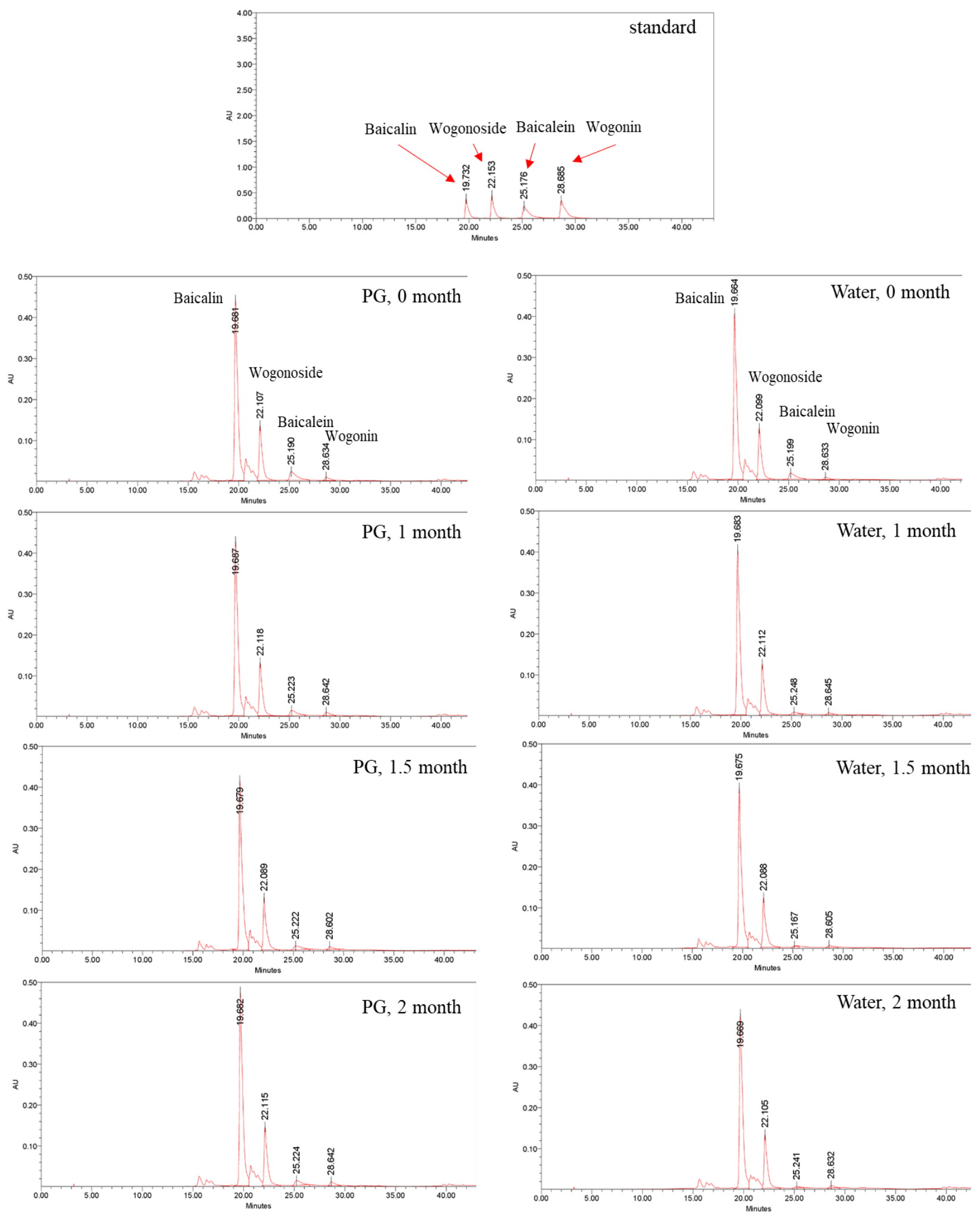

Figure 2. HPLC chromatograms of baicalin, wogonoside, baicalein and wogonin from the Scutellaria baicalensis extract (SBE) stored in $20 \%$ PG or water for different numbers of months. 
Table 1. The ingredient retained \% of SBE storage for different months in 20\% PG and water.

\begin{tabular}{|c|c|c|c|c|c|c|c|c|}
\hline \multicolumn{3}{|c|}{ SBE (mg/g) } & \multicolumn{3}{|c|}{ 20\% PG (Retained\%) } & \multicolumn{3}{|c|}{ Water (Retained\%) } \\
\hline Storage time & & 0 month & 1 month & 1.5 months & 2 months & 1 month & 1.5 months & 2 months \\
\hline Baicalin & $270.05 \pm 2.71$ & 100.00 & $98.25 \pm 2.16^{\mathrm{a}}$ & $98.89 \pm 4.55^{\mathrm{a}}$ & $98.21 \pm 1.98^{a}$ & $99.20 \pm 3.79^{a}$ & $97.07 \pm 2.95^{\mathrm{a}}$ & $92.41 \pm 1.84^{b}$ \\
\hline Wogonoside & $57.50 \pm 4.32$ & $100.00^{\mathrm{a}}$ & $97.61 \pm 5.93^{\mathrm{a}}$ & $96.15 \pm 6.39^{a}$ & $80.85 \pm 3.11^{b}$ & $83.84 \pm 2.10^{b}$ & $80.94 \pm 3.66^{\mathrm{b}}$ & $72.33 \pm 2.13^{c}$ \\
\hline Baicalein & $19.24 \pm 1.01$ & $100.00^{\mathrm{a}}$ & $98.19 \pm 2.14^{\mathrm{a}}$ & $92.23 \pm 6.87^{b}$ & $84.28 \pm 1.80^{c}$ & $52.05 \pm 3.89^{d}$ & $47.18 \pm 2.81^{d}$ & $44.43 \pm 8.09^{d}$ \\
\hline Wogonin & $8.61 \pm 0.89$ & $100.00^{\mathrm{a}}$ & $99.89 \pm 7.67^{\mathrm{a}}$ & $98.10 \pm 1.70^{\mathrm{a}}$ & $83.82 \pm 2.21^{\mathrm{c}}$ & $98.93 \pm 1.90^{\mathrm{a}}$ & $92.76 \pm 5.93^{b}$ & $87.52 \pm 2.05^{\mathrm{c}}$ \\
\hline
\end{tabular}

The data are presented as the mean $\pm \mathrm{SD}(\mathrm{n}=3)$. Letters indicate significant differences within each experiment at $p<0.05$.

3.2. Effects of SBE Storage in $20 \%$ PG and Water on the Antibacterial Activities against P. acnes and S. aureus

P. acnes and S. aureus live in close proximity to each other on human skin, and both bacterial species can be isolated from acne vulgaris-affected skin sites. P. acnes, a grampositive anaerobic bacterium, may play a major role in the initiation of the inflammatory reaction by stimulating the secretion of cytokines [22]. S. aureus, a Gram-positive aerobic bacterium, shows increased numbers in acne lesions [23]. A disturbed microorganism balance can impact skin health and might initiate or support the events that lead to skin disorders [24]. For the application of skin care products, we first analyzed the antibacterial activities of the SBE.

Regardless of the $20 \%$ PG or water solvent group, the relative antibacterial activities decreased over time. The relative anti-P. acnes activity of the water solvent group stored at months 1.0, 1.5 and 2.0 was significantly lower than that of the $20 \%$ PG solvent group (Figure 3A). Similar results were also shown for S. aureus, in which the water solvent group stored at months 1.5 and 2.0 had significantly lower relative antibacterial activity than the 20\% PG solvent group (Figure 3B). Lu et al. [25] and Qiu et al. [26] both reported that baicalein has strong anti-S. aureus activity, and four flavones have anti-S. aureus activity in the order of baicalein $>$ baicalin $>$ wogonin $>$ wogonoside [26]. This is presumably because of the significant decay of wogonoside and baicalein in the water solvent group during storage (Table 1), which reduces the antibacterial activity.

\subsection{Effects of SBE Storage in $20 \%$ PG and Water on the Antioxidant Activity}

Antioxidants have been shown to prevent the oxidative stress of free radicals associated with the pathogenesis of a number of chronic diseases, including inflammationassociated disorders [27]. A study has shown that higher antioxidant activities, based on DPPH radical scavenging, have an impact on the anti-inflammatory effects [28]. Therefore, we analyzed the DPPH radical scavenging activity of the $20 \%$ PG and water solvent groups to understand their anti-inflammatory potential. Figure 4 shows that with increasing storage time, the DPPH radical scavenging activity decreased, and the EC50 values for Log dilution-fold of the $20 \%$ PG group were higher than those of the water groups. Woźniak et al. [29] reported that the order of DPPH radical scavenging activity was baicalein > baicalin > wogonoside > wogonin, and the total antioxidant properties of S. baicalensis come mainly from baicalein with some contribution from baicalin, wogonoside and wogonin. It has been suggested that the SBE was more stable in $20 \%$ PG solution and maintained better antioxidant activity, and the decrease in DPPH radical scavenging activity might be related to the degradation of baicalein (Table 1). 


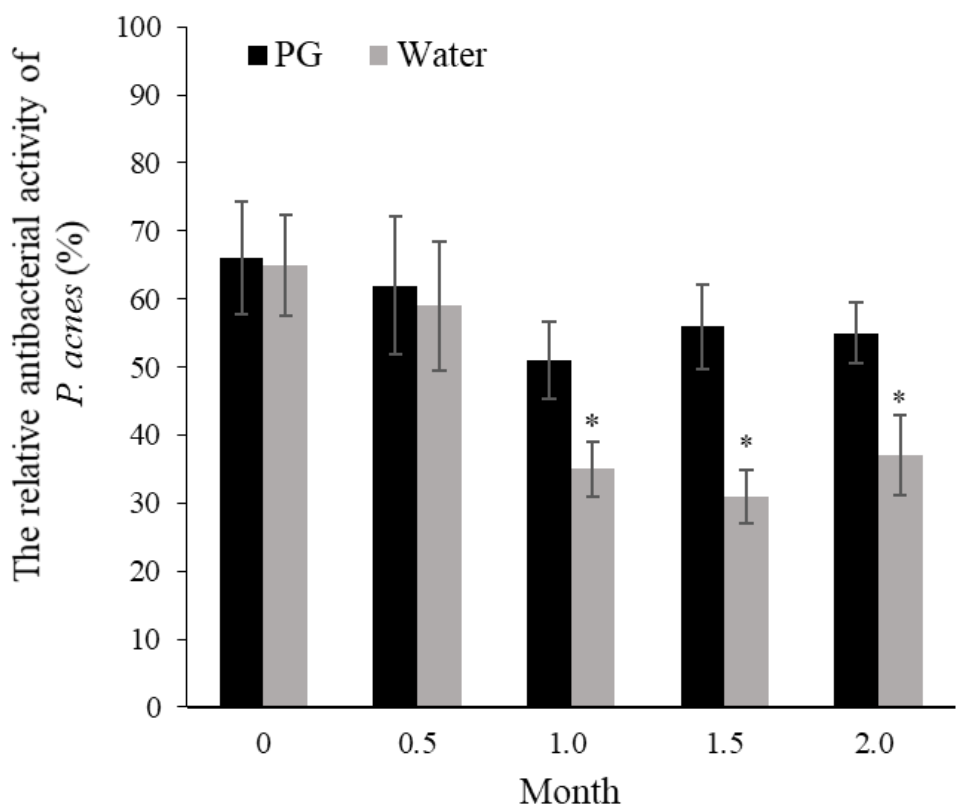

(A)

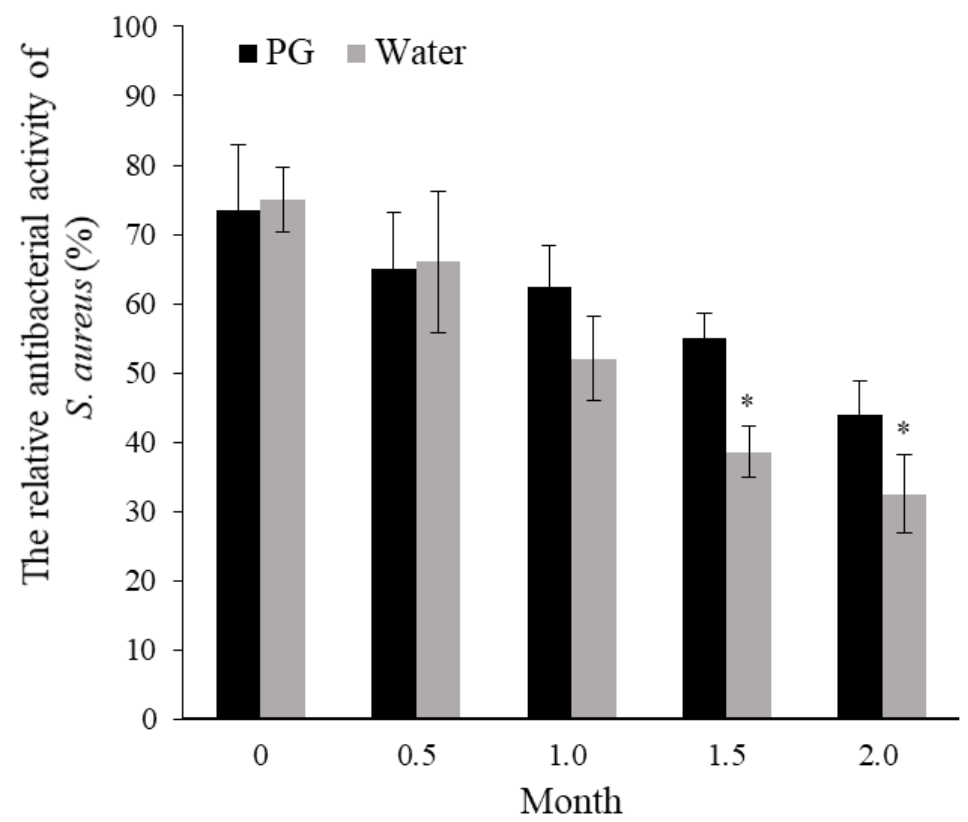

(B)

Figure 3. The antibacterial activities against P. acnes (A) and S. aureus (B) of the Scutellaria baicalensis extract (SBE) stored in 20\% PG and water for different numbers of months. The data are presented as the mean $\pm \operatorname{SD}(\mathrm{n}=3)$. ${ }^{*} p<0.05$ compared with the $20 \%$ PG solvent. 


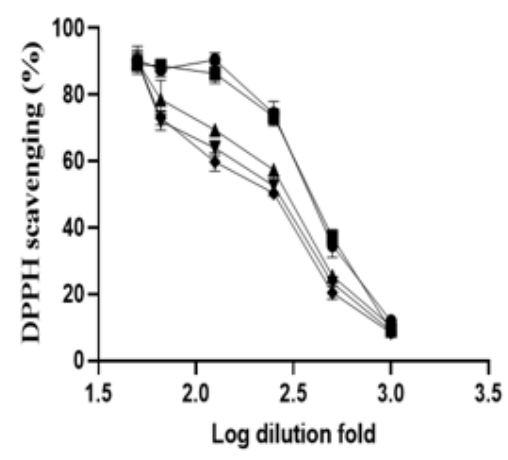

- PG, 0 month

- PG, 0.5 month

^ PG, 1.0 month

₹-PG,1.5 month

- PG, 2.0 month

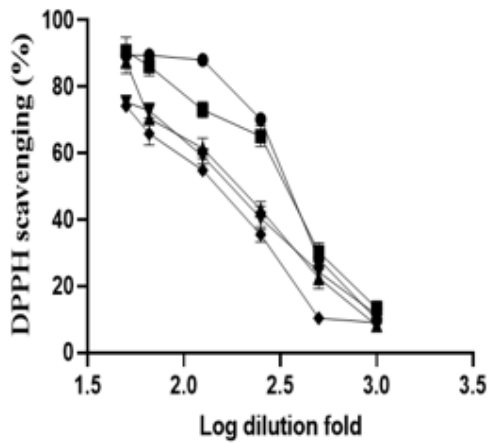

(A)

\begin{tabular}{|c|c|c|c|c|c|}
\hline & \multicolumn{5}{|c|}{ EC50 (Log dilution fold, mean \pm SD) } \\
\hline Storage time (Month) & 0 & 0.5 & 1 & 1.5 & 2 \\
\hline PG & $2.58 \pm 0.03^{\mathrm{a}}$ & $2.57 \pm 0.01^{\mathrm{a}}$ & $2.39 \pm 0.02^{\mathrm{b}}$ & $2.32 \pm 0.02^{\mathrm{c}}$ & $2.29 \pm 0.01^{\mathrm{c}}$ \\
\hline Water & $2.53 \pm 0.01^{\mathrm{a}}$ & $2.48 \pm 0.02^{\mathrm{b}}$ & $2.26 \pm 0.02^{\mathrm{c}}$ & $2.22 \pm 0.01^{\mathrm{c}}$ & $2.11 \pm 0.02^{\mathrm{d}}$ \\
\hline
\end{tabular}

(B)

Figure 4. The antiradical activity (A) and EC50 (B) of the Scutellaria baicalensis extract (SBE) stored in $20 \%$ PG and water for different numbers of months. The data are presented as the mean $\pm \operatorname{SD}(n=3)$. Letters indicate significant differences within each group at $p<0.05$.

\subsection{Effects of SBE Storage in $20 \%$ PG and Water on Anti-Inflammatory Activity in Human Keratinocytes}

Keratinocytes express and release inflammatory mediators in response to skin inflammation and pro-inflammatory cytokines such as IL-1 $\beta$ during the progression phase of the inflammatory process [30]. Ponec et al. [31] reported that more than 5\% PG would affect the growth of keratinocyte, and Hoh and Maier [32] also reported that around $1317 \mathrm{mM}$ PG (around 10\% PG) causes a 50\% decrease in absorbance of viable keratinocyte. In our present study, CRL-2309 cells were exposed to 0.1\% PG under cell culture, so we suggested that the concentration of PG would not induce inflammation of CRL-2309 cells. Moreover, flavonoids with high reactive oxygen species (ROS) scavenging activity have been shown to exhibit anti-inflammatory activity [33]. The baicalein in 20\% PG had significantly less decay and better antioxidant capacity than that in water after one month of storage (Table 1 and Figure 4B). Next, we induced keratinocyte inflammation with $\mathrm{tBuOOH}$, a representative radical source in a biochemical study [34], and analyzed the ability of samples to inhibit IL-1 $\beta$ and intracellular ROS production.

The production of generated intracellular ROS and IL-1 $\beta$ was significantly elevated by $\mathrm{tBuOOH}$ in CRL-2309 cells. It was observed that $20 \% \mathrm{PG}$ and water $(50 \mu \mathrm{g} \mathrm{SBE} / \mathrm{mL})$ at month 0 could strongly inhibit intracellular ROS and IL-1 $\beta$ production. When the storage time was extended to one month, the inflammatory inhibition from the $20 \%$ PG group was significantly better than that of the water group (Figure 5). Chi et al. [35] reported that $S$. baicalensis lowers IL- $1 \beta$ in subchronic and acute skin inflammation in vivo. It has been suggested that $S$. baicalensis can be a useful therapeutic agent for skin inflammatory disorders, and preparing a suitable solvent for short-term storage, such as $20 \%$ PG, could effectively retain its anti-inflammatory abilities. Furthermore, Olennikov et al. [36] have identified the structures of 125 phenolic compounds from S. baicalensis. Therefore, we suggested that $20 \%$ PG solvent not only maintained the stability of baicalin, wogonoside and wogonin, but also caused other phenolic substances to maintain their stability and to retain antioxidant activity and anti-inflammatory activity. 


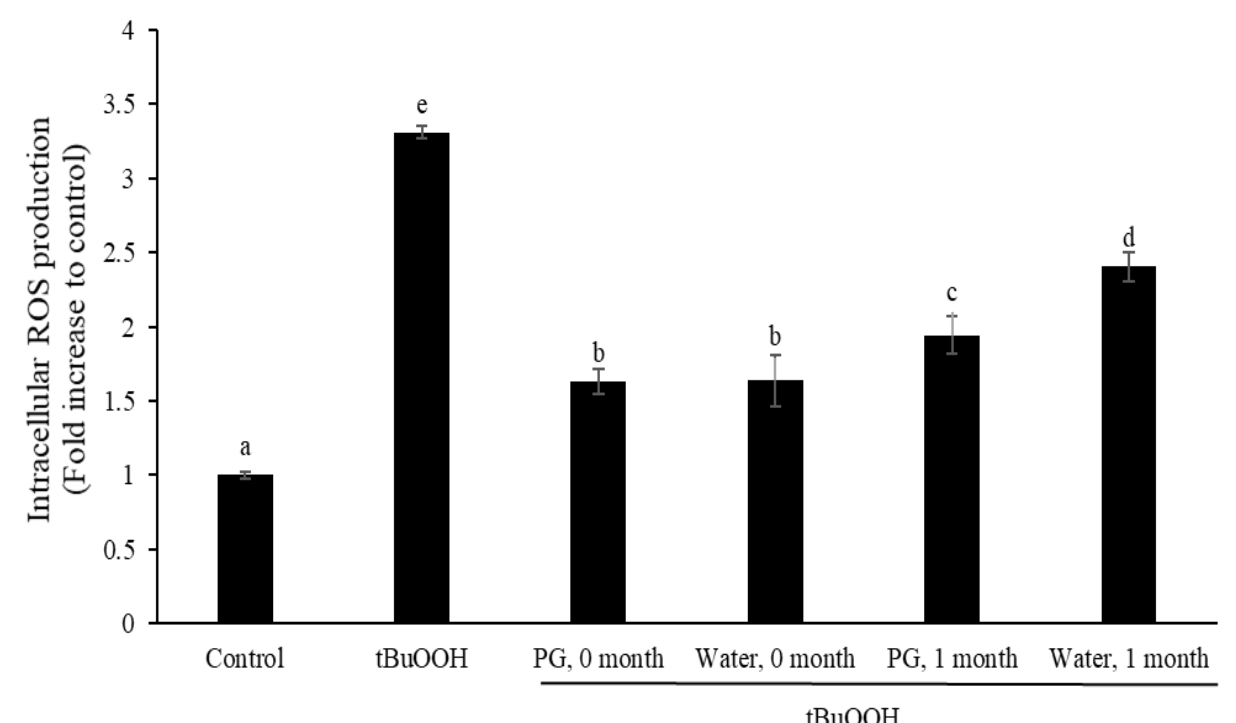

(A)

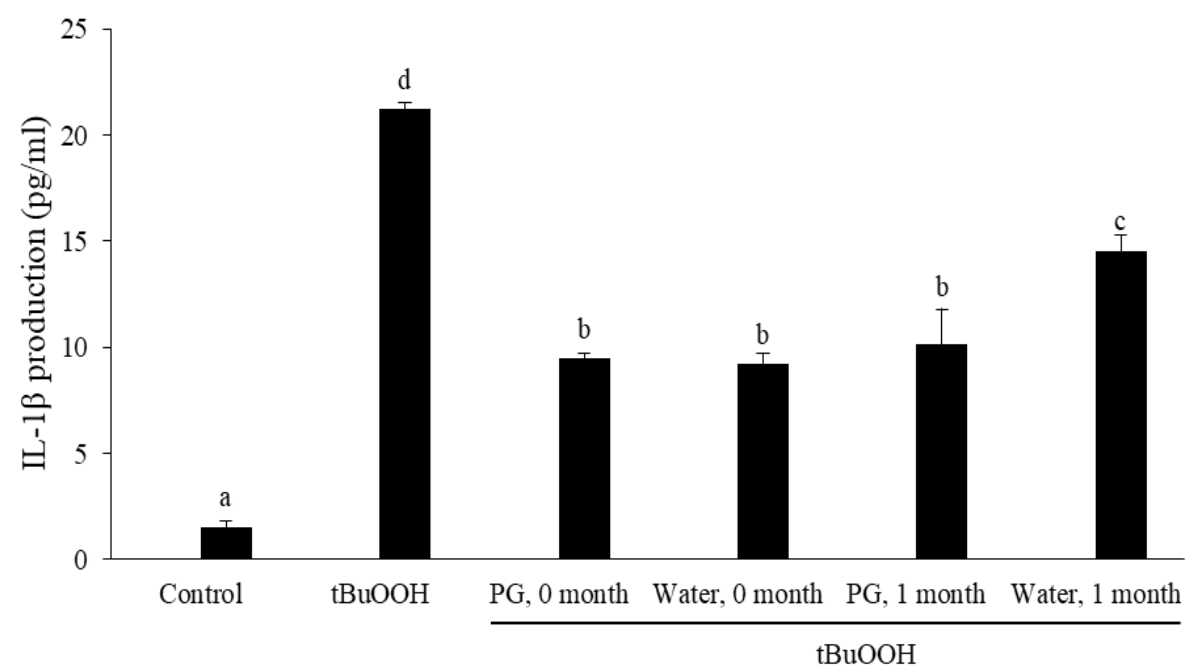

(B)

Figure 5. Effects of Scutellaria baicalensis extract (SBE) storage in $20 \%$ PG and water for one month on intracellular ROS (A) and IL-1 $\beta$ (B) production by $\mathrm{tBuOOH}$ stimulation in human keratinocytes. The data are presented as the mean $\pm \mathrm{SD}(\mathrm{n}=3)$. Letters indicate significant differences within each experiment at $p<0.05$.

\subsection{Effects of SBE Storage in 20\% PG and Water on the Phototoxicity Potential with Human Keratinocytes}

Phototoxicity is a growing concern in dermatology due to stratospheric ozone depletion resulting in an increasing penetration of $\mathrm{UV}$ radiation. $\mathrm{CPZ}$ is a phototoxicant of keratinocytes. Upon UV irradiation, CPZ produces a variety of free radicals, including the corresponding cation radical, the neutral promazinyl radical, a chlorine radical and a super-centered peroxy radical. The neutral promazinyl radical can react covalently with the cell membrane, proteins and other macromolecules to yield antigens that could be responsible for the photoallergic response to $\mathrm{CPZ}$, resulting in phototoxicity [37]. In the current study, CPZ was used as a positive control and, as expected, exhibited phototoxic activity in CRL-2309 cells. The effect of the solvent used in storage may be of concern to the alternating phototoxic risk of the SBE. As the results show, the application of $50 \mu \mathrm{g}$ $\mathrm{SBE} / \mathrm{mL}, 20 \%$ PG and water did not induce phototoxicity at months 0,1 and 2 (Figure 6). 
It was suggested that regardless of whether the SBE was stored in PG or water, it would not become a photosensitizing agent.

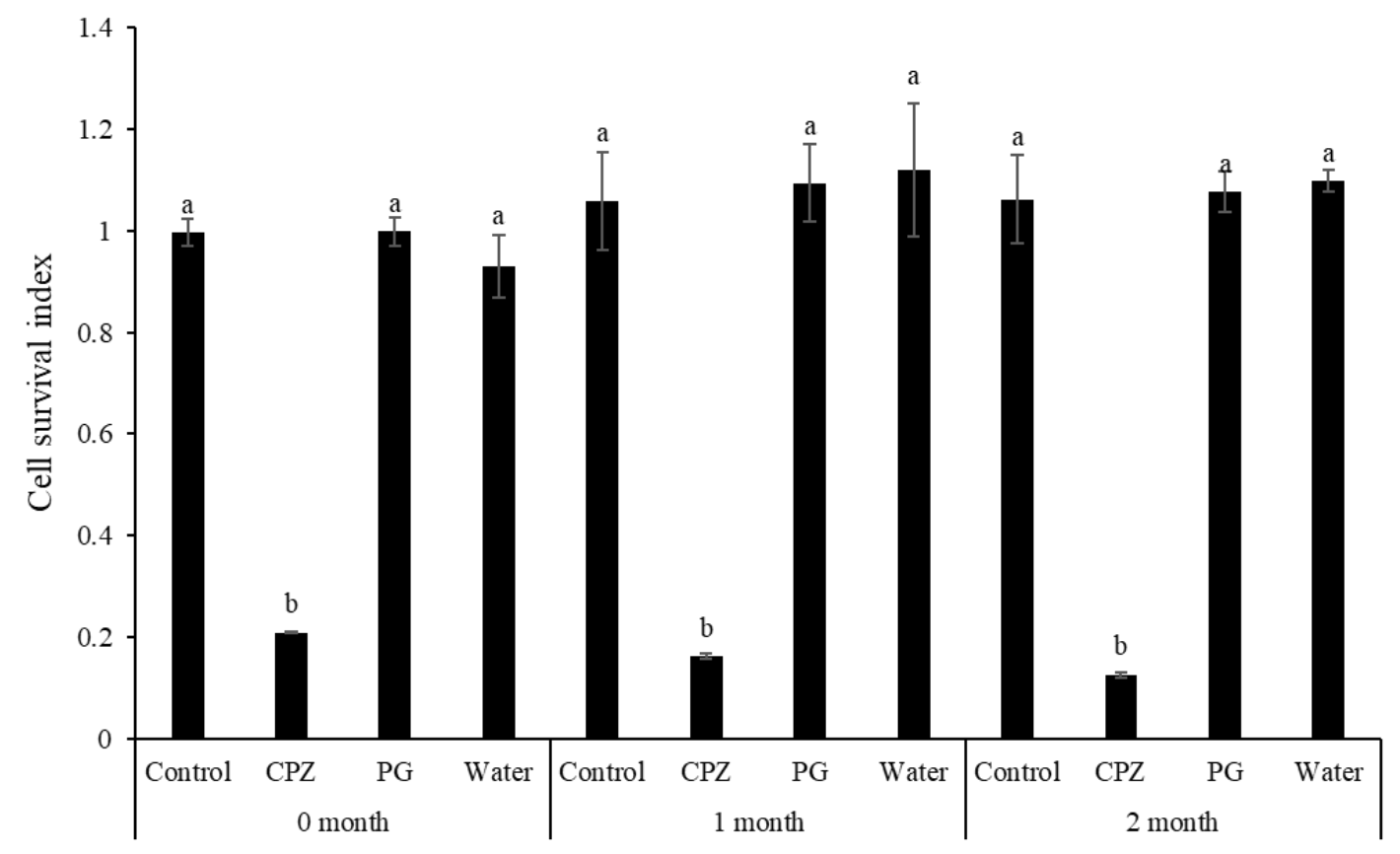

Figure 6. Evaluation of the phototoxic potential under UVA exposure of Scutellaria baicalensis extract (SBE) stored in $20 \%$ PG and water for different numbers of months to human keratinocytes. The data are presented as the mean $\pm \operatorname{SD}(n=3)$. Letters indicate significant differences within each experiment at $p<0.05$.

\section{Conclusions}

Here, we have demonstrated that PG was a good choice of solvent for the short-term storage of the SBE for at least two months, and only the concentration of $20 \%$ used in this study could retain more than $80 \%$ ingredient availability, including baicalin, wogonoside, baicalein and wogonin. This solvent could also maintain anti-inflammatory activity and did not increase the phototoxic risk. PG is a common, safe and inexpensive additive for many industries. Thus, our findings provide a convenient and efficient way to improve the issues of SBE activity loss in storage and may extend further industrial applications.

Author Contributions: Conceptualization, T.-T.K. and P.-A.H.; Methodology, M.-C.W., Y.-H.C. and Y.-T.C.; Validation, T.-T.K. and P.-A.H.; Investigation, M.-C.W. and Y.-H.C.; Data Curation, M.-C.W., Y.-H.C., Y.-T.C. and T.-T.K.; Writing, P.-A.H. and T.-T.K. All authors have read and agreed to the published version of the manuscript.

Funding: This research was funded by the Council of Agriculture, Executive Yuan R.O.C. from grant number 110AS-10.1.7-AD-U1, 107AS-13.4.1-ST-a2 and 106AS-16.4.1-ST-a8.

Institutional Review Board Statement: Not applicable.

Informed Consent Statement: Not applicable.

Data Availability Statement: Not applicable.

Acknowledgments: This research was funded by the Council of Agriculture, Executive Yuan R.O.C. from grant number 110AS-10.1.7-AD-U1, 107AS-13.4.1-ST-a2 and 106AS-16.4.1-ST-a8.

Conflicts of Interest: The authors declare no conflict of interest. 


\section{References}

1. Luo, J.L.; Lu, F.L.; Liu, Y.C.; Lo, C.F. Identification of Scutellaria Baicalensis in Traditional Chinese Medicine Preparations by LC/MS/MS Fingerprinting Method. J. Food Drug Anal. 2012, 20, 887-899.

2. Gao, Z.; Huang, K.; Xu, H. Protective effects of flavonoids in the roots of Scutellaria baicalensis Georgi against hydrogen peroxide-induced oxidative stress in HS-SY5Y cells. Pharmacol. Res. 2001, 43, 173-178. [CrossRef] [PubMed]

3. Min, W.; Liu, X.; Qian, Q.; Lin, B.; Wu, D.; Wang, M.; Ahmad, I.; Yusuf, N.; Luo, D. The effects of baicalin against UVA-induced photoaging in skin fibroblasts. Am. J. Chin. Med. 2014, 42, 709-727. [CrossRef]

4. Kim, B.; Kim, J.E.; Lee, S.M.; Kim, H.S. Effect of Scutellaria baicalensis extract on skin barrier function via peroxisome proliferatoractivated receptor- $\alpha$. Korean Korean J. Chem. Eng. 2014, 31, 104-108. [CrossRef]

5. Gabrielska, J.; Oszmiańsk, J.; Żyłka, R.; Komorowska, M. Antioxidant activity of flavones from Scutellaria baicalensis in lecithin liposomes. Z. Naturforsch. C. 1997, 52, 817-823. [CrossRef] [PubMed]

6. Jung, H.S.; Kim, M.H.; Gwak, N.G.; Im, Y.S.; Lee, K.Y.; Sohn, Y.; Choi, H.; Yang, W.M. Antiallergic effects of Scutellaria baicalensis on inflammation in vivo and in vitro. J. Ethnopharmacol. 2012, 141, 345-349. [CrossRef] [PubMed]

7. Tsai, P.J.; Huang, W.C.; Hsieh, M.C.; Sung, P.J.; Kuo, Y.H.; Wu, W.H. Flavones isolated from Scutellariae radix suppress propionibacterium acnes-induced cytokine production in vitro and in vivo. Molecules 2016, 21, 15. [CrossRef]

8. Ni, H.; Wu, Z.; Muhammad, I.; Lu, Z.; Li, J. Optimization of baicalin water extraction process from Scutellaria baicalensis (a traditional Chinese medicine) by using orthogonal test and HPLC. Rev. Bras. Farm. Farmacogn. 2018, 28, 151-155. [CrossRef]

9. Choi, W.; Kwon, H.S.; Lee, H.Y. Enhancement of anti-skin inflammatory activities of Scutellaria baicalensis using an alkaline reduced water extraction process. Food Sci. Biotechnol. 2014, 23, 1859-1866. [CrossRef]

10. World Health Organization. Stability testing of active pharmaceutical ingredients and finished pharmaceutical products. WHO Tech. Rep. Ser. 2009, 953, 87-123.

11. Xing, J.; Chen, X.; Zhong, D. Stability of baicalin in biological fluids in vitro. J. Pharmaceut. Biomed. 2005, 39, 593-600. [CrossRef] [PubMed]

12. Qiu, F.; Tang, X.; He, Z.G.; Li, H.Z. Stability of baicalin aqueous solution by validated RP-HPLC. J. Chin. Pharm. 2004, 13, 134-137.

13. Feng, Z.; Zhou, J.; Shang, X.; Kuang, G.; Han, J.; Lu, L.; Zhang, L. Comparative research on stability of baicalin and baicalein administrated in monomer and total flavonoid fraction form of Radix scutellariae in biological fluids in vitro. Pharm. Biol. 2017, 55, 1177-1184. [CrossRef] [PubMed]

14. Moldovan, B.; David, L.; Chişbora, C.; Cimpoiu, C. Degradation kinetics of anthocyanins from European cranberrybush (Viburnum opulus L.) fruit extracts. Effects of temperature, pH and storage solvent. Molecules 2012, 17, 11655-11666. [CrossRef] [PubMed]

15. Propylene Glycol and Esters. Available online: https:/ / www.ema.europa.eu/en/propylene-glycol-esters (accessed on 13 May 2021).

16. Okawa, M.; Kinjo, J.; Nohara, T.; Ono, M. DPPH (1, 1-diphenyl-2-picrylhydrazyl) radical scavenging activity of flavonoids obtained from some medicinal plants. Biol. Pharm. Bull. 2001, 24, 1202-1205. [CrossRef]

17. Sittisart, P.; Chitsomboon, B. Intracellular ROS scavenging activity and downregulation of inflammatory mediators in RAW264. 7 macrophage by fresh leaf extracts of Pseuderanthemum palatiferum. Evid. Based Complement. Altern. Med. 2014, $2014,309095$. [CrossRef]

18. Amaral, L.F.; Moriel, P.; Foglio, M.A.; Mazzola, P.G. Evaluation of the cytotoxicity and phototoxicity of Caryocar brasiliense supercritical carbon dioxide extract. Bmc Complementary Altern. Med. 2014, 14, 450. [CrossRef]

19. Anwer, M.K.; Al-Shdefat, R.; Jamil, S.; Alam, P.; Abdel-Kader, M.S.; Shakeel, F. Solubility of bioactive compound hesperidin in six pure solvents at (298.15 to 333.15) K. J. Chem. Eng. Data. 2014, 59, 2065-2069. [CrossRef]

20. Rhys, N.H.; Gillams, R.J.; Collins, L.E.; Callear, S.K.; Lawrence, M.J.; McLain, S.E. On the structure of an aqueous propylene glycol solution. J. Chem. Phys. 2016, 145, 224504. [CrossRef]

21. Allen, J.L. Quality Control: Water activity considerations for beyond-use dates. Int. J. Pharm. Compd. 2018, 22, $288-293$.

22. Koreck, A.; Pivarcsi, A.; Dobozy, A.; Kemeny, L. The role of innate immunity in the pathogenesis of acne. Dermatology 2003, 206, 96-105. [CrossRef] [PubMed]

23. Degitz, K.; Ochsendorf, F. Acne. J. Dtsch. Dermatol. Ges. 2017, 15, 709-722. [CrossRef] [PubMed]

24. Van Rensburg, J.J.; Lin, H.; Gao, X.; Toh, E.; Fortney, K.R.; Ellinger, S.; Zwickl, B.; Janowicz, D.M.; Katz, B.P.; Nelson, D.E. The human skin microbiome associates with the outcome of and is influenced by bacterial infection. MBio 2015, 6, e01315-15. [CrossRef]

25. Lu, Y.; Joerger, R.; Wu, C. Study of the chemical composition and antimicrobial activities of ethanolic extracts from roots of Scutellaria baicalensis Georgi. J. Agric. Food Chem. 2011, 59, 10934-10942. [CrossRef] [PubMed]

26. Qiu, F.; Meng, L.; Chen, J.; Jin, H.; Jiang, L. In vitro activity of five flavones from Scutellaria baicalensisin combination with Cefazolin against methicillin resistant Staphylococcus aureus (MRSA). Med. Chem. Res. 2016, 25, 2214-2219. [CrossRef]

27. Temple, N. Antioxidants and disease: More questions than answers. Nutr. Res. 2000, 20, 449-459. [CrossRef]

28. Ju, M.J.; Do, J.R.; Kwon, J.H.; Kim, H.K. Physiological activities of mistletoe extracts from Viscum album L. J. Korean Soc. Food Sci. Nutr. 2009, 38, 529-534. [CrossRef]

29. Woźniak, D.; Dryś, A.; Matkowski, A. Antiradical and antioxidant activity of flavones from Scutellariae baicalensis radix. Nat. Prod. Res. 2015, 29, 1567-1570. [CrossRef] 
30. Rox, J.M.; Reinartz, J.; Kramer, M.D. Interleukin-1 $\beta$ upregulates tissue-type plasminogen activator in a keratinocyte cell line (HaCaT). Arch. Dermatol. Res. 1996, 288, 554-558. [CrossRef] [PubMed]

31. Ponec, M.; Haverkort, M.; Soei, Y.L.; Kempenaar, J.; Bodde, H. Use of human keratinocyte and fibroblast cultures for toxicity studies of topically applied compounds. J. Pharm. Sci. 1990, 79, 312-316. [CrossRef] [PubMed]

32. Hoh, A.; Maier, K. Comparative Cytotoxicity Test with Human Keratinocytes, HaCaT Cells, and Skin Fibroblasts to Investigate Skin-Irritating Substances. In Cell and Tissue Culture Models in Dermatological Research; Bernd, A., Bereiter-Hahn, J., Hevert, F., Holzmann, H., Eds.; Springer: Berlin/Heidelberg, Germany, 1993; pp. 341-347.

33. Pandey, K.B.; Rizvi, S.I. Current understanding of dietary polyphenols and their role in health and disease. Curr. Nutr. Food Sci. 2009, 5, 249-263. [CrossRef]

34. Xiao, L.; Takada, H.; Maeda, K.; Haramoto, M.; Miwa, N. Antioxidant effects of water-soluble fullerene derivatives against ultraviolet ray or peroxylipid through their action of scavenging the reactive oxygen species in human skin keratinocytes. Biomed. Pharmacother. 2005, 59, 351-358. [CrossRef] [PubMed]

35. Chi, Y.S.; Lim, H.; Park, H.; Kim, H.P. Effects of wogonin, a plant flavone from Scutellaria radix, on skin inflammation: In vivo regulation of inflammation-associated gene expression. Biochem. Pharmacol. 2003, 66, 1271-1278. [CrossRef]

36. Olennikov, D.N.; Chirikova, N.K.; Tankhaeva, L.M. Phenolic compounds of Scutellaria baicalensis Georgi. Russ. J. Bioorg. Chem. 2010, 36, 816-824. [CrossRef]

37. Reid, L.; Khammo, N.; Clothier, R.H. An evaluation of the effects of photoactivation of bithionol, amiodarone and chlorpromazine on human keratinocytes in vitro. Altern. Lab. Anim. 2007, 35, 471-485. [CrossRef] [PubMed] 